\title{
Biomedical Engineering Education and the Special COVID-19 Issue
}

\author{
(Published online 29 November 2020)
}

Welcome to the inaugural issue of Biomedical Engineering Education! The creation of an education focused biomedical engineering journal has been a priority for Ann Saterbak for 5 years. Three years ago, the three of us came together and mobilized the effort. In early 2020, with leadership from George Truskey, BMES Publications Board Chair, we finalized an agreement with BMES and Springer for a 2021 launch.

The recent COVID-19 global pandemic only expedited our timeline. Recognizing the educational challenges our community is facing, Michele Grimm, AIMBE Academic Council Chair, challenged us to accelerate our launch and assemble papers that could be resources for our community for the 2020 fall semester.

In the spirit of Dr. Grimm's challenge, we are proud to present our first issue, a Special Issue devoted to teaching during the COVID-19 pandemic. Radical changes were thrust upon the education community in spring 2019, and many of those changes are continuing into the fall 2020 semester. While the first printing of Biomedical Engineering Education is not until January 2021, we seized this opportunity for an online "soft launch" in summer 2020, focused on helping faculty teach in an online environment.

All the articles in this Special Issue are Teaching Tips. This article type is new for many of us, but is laser-focused on a specific educational "tip" - such as a new method for evaluating prototypes online, an alternate biomaterials lab, or engaging students with games on Zoom. Written in a deductive style, each paper describes a novel innovation that readers can apply to their class. The authors also reflect on their implementation and link their innovation to research or practice in engineering education. In this way, the papers are grounded in the literature, but are written to facilitate transfer to the (virtual) classroom.

It is clear that the biomedical engineering community is ready for Biomedical Engineering Education. Over 80 papers were submitted in 4 weeks for the Special Issue! This amazing response demonstrates a significant unmet need: the need to document and share best practices in BME education. The journal is fortunate to have strong support from educators around the world, as over 70 people stepped up to participate in rigorous peer review.

Our vision for Biomedical Engineering Education is to be an interdisciplinary, international journal that presents articles on the practice and scholarship of education in bioengineering, biomedical engineering, and its allied fields. Biomedical Engineering Education will document and share advances as educators support students' learning in these rapidly evolving fields. When the journal officially launches in 2021, Biomedical Engineering Education will include a range of paper types, including Research, Innovation, Teaching Tips, Perspectives, and Review articles. Articles will address curriculum design; engineering education research; novel course content, laboratory experiments and demonstrations; program highlights; assessment of teaching and learning in BME; P-12 educational outreach in BME; and advising and professional development of BME students. We welcome your submissions to the journal at any time!

\section{Ann SATERbak}

Department of Biomedical Engineering

Duke University, 101 Science Dr, Durham, NC, USA

Electronic mail: ann.saterbak@duke.edu

Aileen Huang-SAAD

Department of Biomedical Engineering University of Michigan, Ann Arbor, MI, USA

Brian P. Helmke

Department of Biomedical Engineering University of Virginia, P.O. Box 800759, Charlottesville, VA, USA

Publisher's Note Springer Nature remains neutral with regard to jurisdictional claims in published maps and institutional affiliations. 